\title{
Effect of bioactive glass addition on the physical properties of mineral trioxide aggregate
}

\author{
Jei Kim ${ }^{1 \dagger}$, Hyun-Jung Kim² ${ }^{2+}$, Seok Woo Chang $^{3}$, Soram Oh ${ }^{3}$, Sun-Young Kim ${ }^{4}$ Kyoung-Kyu Choi ${ }^{3}$, \\ Duck-Su Kim ${ }^{3}$ and Ji-Hyun Jang ${ }^{3^{*}}$ (D)
}

\begin{abstract}
Background: The addition of bioactive glass (BG), a highly bioactive material with remineralization potential, might improve the drawback of weakening property of mineral trioxide aggregates (MTA) when it encounters with body fluid. This study aims to evaluate the effect of BG addition on physical properties of MTA.

Methods: ProRoot (MTA), and MTA with various concentrations of BG $(1,2,5$ and 10\% BG/MTA) were prepared. Simulated body fluid (SBF) was used to investigate the effect of the storage solution on dentin remineralization. Prepared specimens were examined as following; the push-out bond strength to dentin, compressive strength, setting time solubility and X-ray diffraction (XRD) analysis.

Results: The 2\% BG/MTA showed higher push-out bond strengths than control group after 7 days of SBF storage. The 2\% BG/MTA exhibited the highest compressive strength. Setting times were reduced in the 1 and 2\% BG/MTA groups, and solubility of all experimental groups were clinically acceptable. In all groups, precipitates were observed in dentinal tubules via SEM. XRD showed the increased hydroxyapatite peaks in the 2, 5 and 10\% BG/MTA groups.

Conclusion: It was verified that the BG-added MTA increased dentin push-out bond strength and compressive strength under SBF storage. The addition of BG did not negatively affect the MTA maturation reaction; it increased the amount of hydroxyapatite during SBF maturation.
\end{abstract}

Keywords: Mineral trioxide aggregate, Bioactive glass, Pushout bond strength, Compressive strength, Set-ting time, X-ray diffraction analysis

\section{Introduction}

Mineral trioxide aggregate (MTA) was introduced in 1993 [1] and has been used in the repair of root perforations, capping of pulps with reversible pulpitis, apexification, and as a root-end filling material, because of its sealing ability and biocompatibility [2]. The main component of the MTA powder is calcium silicate, which is

\footnotetext{
* Correspondence: jangjihyun@khu.ac.kr

†Jei Kim and Hyun-Jung Kim contributed equally to this work.

${ }^{3}$ Department of Conservative Dentistry, School of Dentistry, Kyung Hee

University, 26 Kyungheedae-ro, Dongdaemun-gu, Seoul 02447, Republic of Korea

Full list of author information is available at the end of the article
}

formed by the reaction of $\mathrm{CaO}$ and $\mathrm{SiO}_{2}$. Through the hydration process with distilled water (DW), MTA forms calcium silicate hydrate and calcium hydroxide in the form of a crystalline phase in the set MTA, followed by hydroxyapatite $\left(\mathrm{Ca}_{10}\left(\mathrm{PO}_{4}\right)_{6}(\mathrm{OH})_{2}\right)$ formation, which has a sealing effect [1]. MTA has been accepted as a suitable endodontic restorative material as it provides favorable histologic and clinical outcomes, because of its effective sealing and biocompatibility [3, 4]. However, several studies have presented the shortcomings of MTA [2, 4-14], including long setting time [1, 2, 5-7], poor handling properties $[6,7]$ and poor physical properties

(c) The Author(s). 2021 Open Access This article is licensed under a Creative Commons Attribution 4.0 International License, which permits use, sharing, adaptation, distribution and reproduction in any medium or format, as long as you give appropriate credit to the original author(s) and the source, provide a link to the Creative Commons licence, and indicate if changes were made. The images or other third party material in this article are included in the article's Creative Commons licence, unless indicated otherwise in a credit line to the material. If material is not included in the article's Creative Commons licence and your intended use is not permitted by statutory regulation or exceeds the permitted use, you will need to obtain permission directly from the copyright holder. To view a copy of this licence, visit http://creativecommons.org/licenses/by/4.0/. The Creative Commons Public Domain Dedication waiver (http://creativecommons.org/publicdomain/zero/1.0/) applies to the data made available in this article, unless otherwise stated in a credit line to the data. 
when interacting with body fluids (BF) [8, 9]. Methods such as adding additives (calcium chloride [10], sodium hydrogen phosphate [12], methylcellulose [10], bioactive glass (BG) [11] or changing the hydration liquid to calcium chloride [7], calcium lactate gluconate [7], and elastin-like polypeptide [6] have been attempted to overcome the disadvantages of MTA; these methods have demonstrated improvements in some properties of MTA.

In most clinical application environments of MTA, more than one surface of the MTA material is in contact with the periodontal or pulpal tissue. When the unset MTA is contaminated with tissue fluid (e.g., blood and interstitial fluid from dental pulp and periodontal tissues), the mechanical properties of MTA are adversely affected [15]. Previous investigations reported that blood contamination has detrimental effects on the resistance of displacement [8], microhardness, compressive strength, and surface microstructure [9]; further, it is associated with changes in the setting reaction of MTA with lower formation of calcium hydroxide crystalline structures [16]. Thus, additives and alternative liquid solutions to improve the properties of MTA need to be addressed in clinically applicable conditions.

In 1969, Dr. Larry Hench introduced BG for the first time; it was an alternative to nearly inert implant materials [17]. It is a highly bioactive material with silicon dioxide as its main component. When it encounters water from $\mathrm{BF}$ or simulated body fluid (SBF), BG immediately undergoes ionic dissolution and glass degradation [17]. It releases silica ions to form a silica-rich layer on the surface. Outside this layer, calcium and phosphoric acid from the BF form a layer of calcium phosphate, which becomes hydroxyapatite when it crystallizes [18]. Further, BG can bond to mineralized and soft tissue [19]; this leads to a superior surface area with a higher dissolution rate and faster apatite formation. In addition, it improves the mechanical properties of such composites for natural bones [18].

Owing to the ability of BG to form apatite, several investigations have been conducted in the recent years to use BG as a remineralization additive in dental restoration materials owing to its ability to form apatite [11, 20]. Jang et al. [21] reported that dental composite resins including BG remineralize surrounding dentin; Kim et al. [22] suggested that a glass ionomer including BG had the same effect. Thus far, there have been a few studies on the addition of BG to MTA; among them, the physical properties of MTA supplemented with BG, which are required for the evaluation of endodontic restorative materials, have been rarely investigated. This study aims to evaluate the effect of BG addition on the physical properties of MTA, which includes push-out bond strength to dentin, compressive strength, setting time, solubility, and X-ray diffraction (XRD) analysis.

\section{Materials and methods Material preparation}

For specimen preparation, DW was used as the liquid solution in all experimental groups. The group names were labeled according to the type of powder used to prepare the MTA specimens. White ProRoot MTA (Dentsply Sirona, Tulsa, USA) was used as the control and labeled as MTA. The major constituents of MTA powder were tricalcium silicate $\left(\mathrm{Ca}_{3} \mathrm{SiO}_{5}\right)$, dicalcium silicate $\left(\mathrm{Ca}_{2} \mathrm{SiO}_{4}\right)$, tricalcium aluminate $\left(\mathrm{Ca}_{3} \mathrm{Al}_{2} \mathrm{O}_{6}\right)$, bismuth oxide $\left(\mathrm{Bi}_{2} \mathrm{O}_{3}\right)$ and calcium sulfate $\left(\mathrm{CaSO}_{4}\right)$. The MTA with BG supplemented groups (BG/MTA groups) were prepared using the MTA and 63S BG (Bonding Chemical, USA) at four different concentrations: 1, 2, 5, and $10 \mathrm{wt} \%$; these were labeled as 1\% BG/MTA, 2\% BG/ MTA, 5\% BG/MTA, and 10\% BG/MTA, respectively. The composition of $63 \mathrm{~S}$ BG was $63 \% \mathrm{SiO}_{2}, 31 \% \mathrm{CaO}$, and $6 \% \mathrm{P}_{2} \mathrm{O}_{5}$, and its particle size was less than $20 \mu \mathrm{m}$. The L/P ratio of DW to the powder was 0.3 throughout the experiments, which was set according to the manufacturer's recommendations.

\section{Preparation of storage solutions}

$27 \mathrm{mM} \mathrm{HCO}_{3}$ - Tris SBF with $\mathrm{pH} 7.4$ was used to investigate the effect of the storage solution on dentin remineralization. The SBF was prepared as described by Tas et al [23] The composition of Tris SBF is listed in Table 1.

\section{Push-out bond strength}

Extracted caries-free human third molars were selected for this study. The included teeth were obtained from patients whose teeth were indicated for extraction, and informed consent was obtained. The experimental protocol using human teeth was reviewed and approved by the Kyung Hee University Institutional Review Board (KHU-1808-1), and all methods were performed in accordance with the Declaration of Helsinki guidelines and

Table 1 Compositions of $27 \mathrm{mM} \mathrm{HCO}_{3}$ - Tris SBF

\begin{tabular}{ll}
\hline Composition & Amount (g/L) \\
\hline $\mathrm{NaCl}$ & 6.547 \\
$\mathrm{NaHCO}_{3}$ & 2.268 \\
$\mathrm{KCl}$ & 0.373 \\
$\mathrm{Na}_{2} \mathrm{HPO}_{4} \cdot 2 \mathrm{H}_{2} \mathrm{O}$ & 0.178 \\
$\mathrm{MgCl}_{2} \cdot 6 \mathrm{H}_{2} \mathrm{O}$ & 0.305 \\
$\mathrm{CaCl}_{2} \cdot 2 \mathrm{H}_{2} \mathrm{O}$ & 0.368 \\
$\mathrm{Na}_{2} \mathrm{SO}_{4}$ & 0.071 \\
$\left(\mathrm{CH}_{2} \mathrm{OH}\right)_{3} \mathrm{CNH}_{2}$ & 6.057
\end{tabular}

${ }^{\mathrm{a} S B F}$ Simulated body fluid 
regulations. The midcoronal portion of the dentin of the tooth was horizontally cut into 2-mm-thick sections using a water-cooled high-speed diamond bur $(n=10)$. A cylindrical cavity $(1.5 \mathrm{~mm}$ diameter) was prepared in each dentin disc with a depth-cutting bur (Microcopy, Kennesaw, GA). The dentin discs were soaked sequentially in $17 \%$ ethylene diamine tetraacetic acid (EDTA) and $2.5 \%$ sodium hypochlorite for $1 \mathrm{~min}$ each, washed with phosphate buffered saline, and dried. Each matrix was mixed with DW and carefully loaded into the cavity without compaction pressure. The specimens were stored at $37^{\circ} \mathrm{C}$ under $95 \%$ humidity for $48 \mathrm{~h}$ [24] and stored in SBF for 3, 7, and 14 days in a $37^{\circ} \mathrm{C}$ cabinet [13]. The SBF solution was replaced every 2 days to prevent autogenous precipitation.

After each storage period, the push-out bond strength was measured using a universal testing machine (AGS$\mathrm{X}$; Shimadzu, Tokyo, Japan) at a $1.0 \mathrm{~mm} / \mathrm{min}$ (diameter $1 \mathrm{~mm}$ ) crosshead speed. The maximum load applied to the specimens in the cavity before dislodgement was recorded in Newtons. The push-out bond strength values in megapascals were calculated by dividing the maximum load by the total contact area of the cavity in $\mathrm{mm}^{2}$ [25].

\section{FE-SEM analysis}

The two remaining samples from each group after the push-out bond strength test (7 days of SBF storage) were placed individually in plastic containers containing $15 \mathrm{ml}$ of SBF ( $\mathrm{pH}=7.4$ ), and they were then stored for an additional 14 days at $37^{\circ} \mathrm{C}$ to analyze the mixture-dentin interface [13]. The SBF solution was replaced every 2 days to prevent autogenous precipitation.

After 14 days of storage in SBF, the specimens were washed in DW and processed for FE-SEM observations. The specimens were cut along the center to expose the internal interface between the MTA and the dentin wall using a high-speed diamond bur under water irrigation. The exposed internal surfaces were serially polished with 600 grit $\mathrm{SiC}$ papers. The smear particles were removed by soaking in a $17 \%$ EDTA solution for $1 \mathrm{~min}$. The specimens were dried at ambient temperature for $24 \mathrm{~h}$. The interfaces were then observed under a FE-SEM (HITA CHI S-4700, at an accelerating voltage of $10 \mathrm{kV}$, Tokyo, Japan) after Pt sputter coating.

\section{Compressive strength}

The compressive strength was determined using the ISO 9917-1 method [26, 27]. Each material was mixed and placed in an acrylic mold $(4.0 \mathrm{~mm}$ inner diameter and $6.0 \mathrm{~mm}$ height) [5]. After the placement, the complete assembly was transferred to a cabinet maintained at $37^{\circ} \mathrm{C}$ under $95 \%$ humidity for a day for complete setting. The specimens were removed from the molds and checked visually for air voids or chipped edges. All defective specimens were discarded.

The specimens were stored in SBF solution for 7 days and maintained at $37^{\circ} \mathrm{C}$ [28-30]. The SBF solution was replaced every 2 days to prevent autogenous precipitation.

The specimens were tested using the universal testing machine at a crosshead speed of $1 \mathrm{~mm} / \mathrm{min}$. The maximum load required to fracture each specimen was measured, and the compressive strength $(\mathrm{C})$ was calculated in megapascals using

$$
\mathrm{C}=4 \mathrm{P} / \pi \mathrm{D}^{2}
$$

where $\mathrm{P}$ denotes the maximum load $(\mathrm{N})$, and $\mathrm{D}$ denote the mean diameter of the specimen $(\mathrm{mm})$.

\section{Etting time}

The setting time was determined according to the International Organization for Standardization (ISO) 9917-1 method using a Gillomore apparatus (Heungjin Co. Ltd., Gyeonggi-do, Korea) [26, 27]. A total of three specimens were prepared in a circular acrylic mold (inner diameter $=10 \mathrm{~mm}$; height $=5 \mathrm{~mm}$ ). The assembly was placed in a cabinet at $37^{\circ} \mathrm{C}$ and $95 \%$ humidity.

The final setting time was measured using a 1-lb heavy needle with a cylindrical tip (diameter $=1.06 \mathrm{~mm}$ ) of the Gillmore apparatus. After mixing for $90 \mathrm{~s}$, the indenter was carefully loaded vertically onto the surface of the specimens and allowed to remain there for $5 \mathrm{~s}$. The indentations were repeated at $30 \mathrm{~s}$ intervals until the needle failed to make a visible indentation in the test specimen to determine the approximate setting time. This process was repeated starting the indentation at 30 $\mathrm{s}$ before the approximate setting time was determined, and indentations were made at $10 \mathrm{~s}$ intervals. This test was repeated five times for each specimen.

\section{Solubility}

The solubility was assessed according to the ISO 6876 standard [27, 31]. A total of eight specimens were evaluated to examine their solubility. Each material was mixed and placed in split-ring molds (internal diameter $=20 \pm 1 \mathrm{~mm}$ and $1.5 \pm 0.1 \mathrm{~mm}$ ). The filled molds were placed in a cabinet maintained at $37^{\circ} \mathrm{C}$ and $95 \%$ humidity for a day. The specimens were removed from the molds and the weight before the DW storage of each specimen was determined to the nearest $0.001 \mathrm{~g}$ using a precision scale (AX200, SHIMADZU, Japan; precision = $0.0001 \mathrm{~g})$.

The specimens were placed in a shallow dish, and $50 \pm 1 \mathrm{~mL}$ of DW was added. The dish was covered and placed in a cabinet maintained at $37^{\circ} \mathrm{C}$ for a day. Then, the specimens were removed and washed with $2-3 \mathrm{~mL}$ of fresh DW on a shallow dish. The water in the dish 
was evaporated without boiling and dried to a constant mass at $110 \pm 2{ }^{\circ} \mathrm{C}$. The dishes were weighed after cooling. The differences between this weight and the original dish weight were divided into the initial weight of the specimens and multiplied by 100 . The results were recorded as the solubility of the specimen. This test was repeated four times for each group.

\section{XRD analysis}

The XRD analysis was performed to compare the compositions of the reactants. Each material was mixed and placed in a rubber mold (inner diameter $=7.0 \mathrm{~mm}$; height $=2.5 \mathrm{~mm}$ ), and it was allowed to fully set during incubation at $37^{\circ} \mathrm{C}$ in a $95 \%$ humidity cabinet for $24 \mathrm{~h}$ [29]. After the setting, the specimens were removed from the molds.

Immediately after setting, half of the spectra $(n=2)$ for each group were examined via XRD using an X-ray diffractometer (PANalytical B. V., Almelo, Netherlands) with $\mathrm{CuKa}$ radiation within a $2 \theta$ range of $5-40^{\circ}$ at a scanning speed of $1.2^{\circ} \mathrm{min}-1$. The $\mathrm{Cu} \mathrm{X}$-ray source was set at an accelerating voltage of $45 \mathrm{kV}$ and a current in the electron beam at $40 \mathrm{~mA}$.

The remaining specimens were examined after 7 days of SBF storage. The specimens were individually stored in SBF using polyethylene containers for 7 days at $37^{\circ} \mathrm{C}$ [30]. The structures of the set specimen and surface deposits formed in the SBF assays were examined using
XRD analysis. The diffraction peak positions were determined using the peak-fitting program (Origin v7.5) software.

\section{Statistical analysis}

The push-out bond strength and compressive strength of groups were analyzed statistically by two-way ANOVA to determine the interaction between variables; one-way ANOVA with Bonferroni test was performed for post hoc test for each variable. The data of the solubility were statistically analyzed using one-way ANOVA with Bonferroni post hoc comparison, respectively. Differences were considered statistically significant at $p<$ 0.05 . All statistical analyses were performed using SPSS (version 22.0; IBM Corp., Armonk, NY).

\section{Results}

\section{Push-out bond strength}

Figure 1 show the push-out bond strength results for all experimental groups. The $2 \%$ BG/MTA group showed a significantly higher value than the control group after 7 days of SBF storage $(p<0.05)$. In the 1 and $2 \%$ BG/MTA groups, the strength of the push-out bond increased as the storage period increased $(p<0.05)$ (Fig. 1), whereas the 5 and $10 \%$ BG/MTA groups did not show significant differences with time.

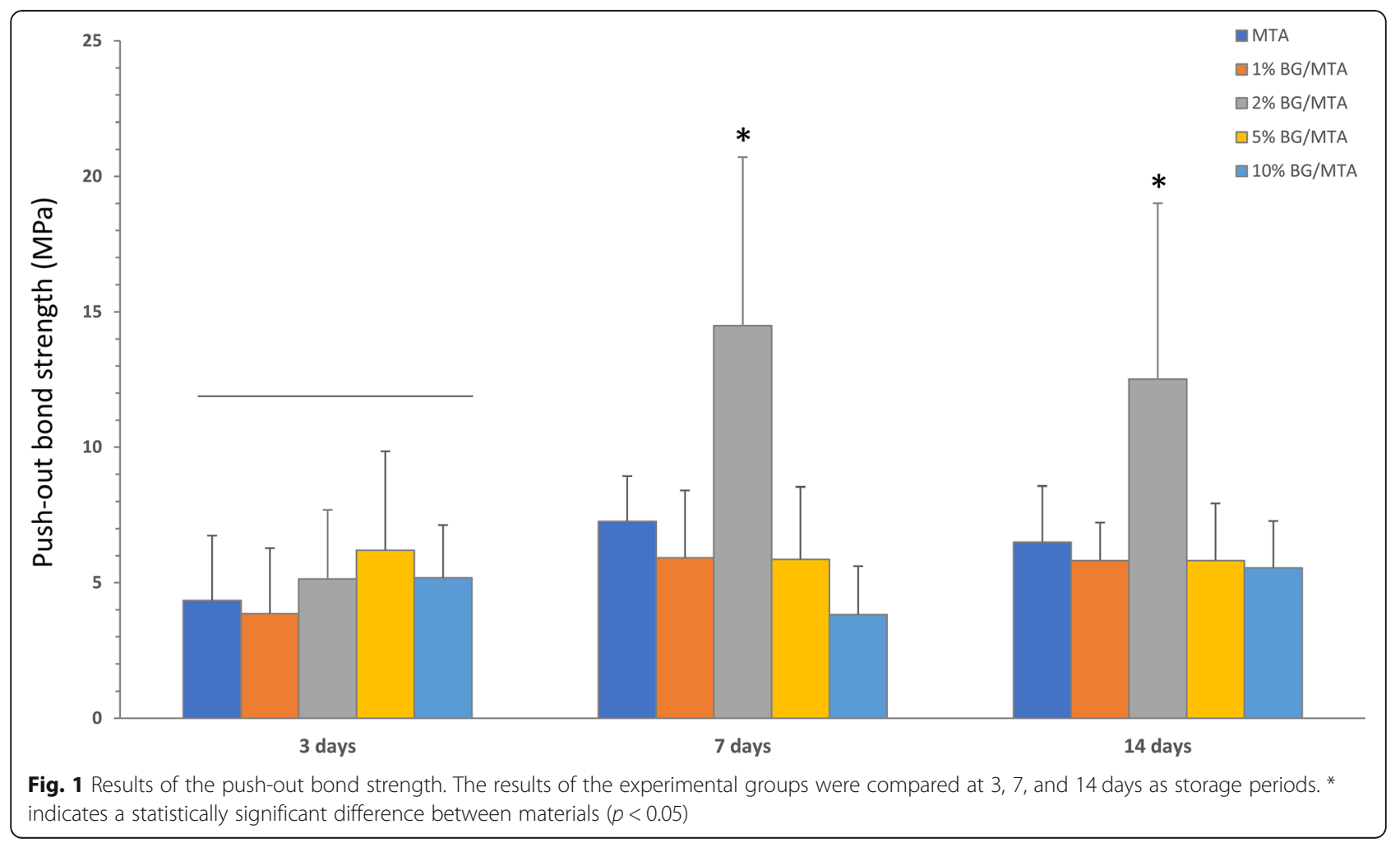



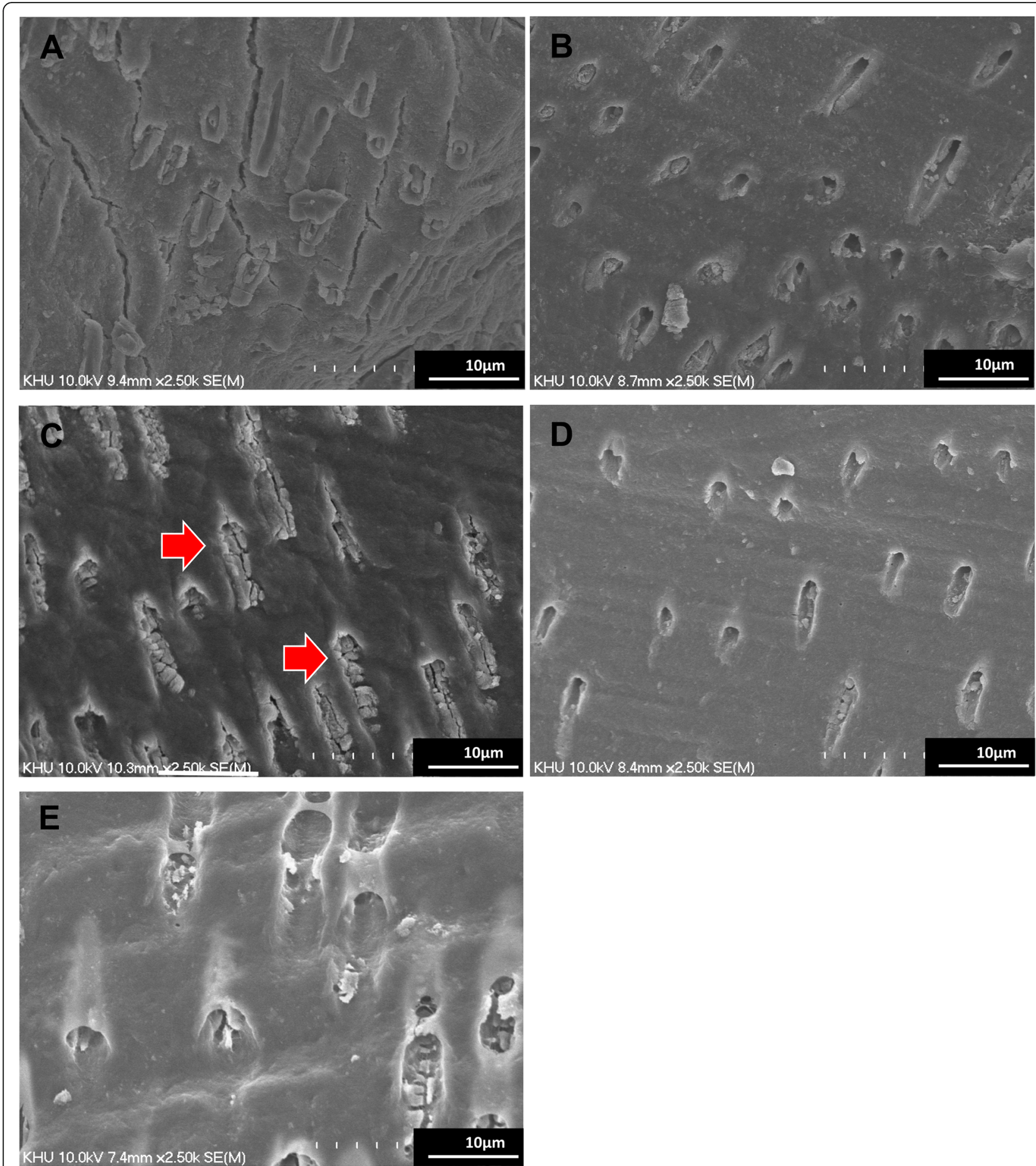

Fig. 2 Representative FE-SEM images of the dentin-MTA interface: 2500 magnification of the interface of A MTA, B 1\% BG/MTA, C 2\% BG/MTA, D $5 \%$ BG/MTA, and E 10\% BG/MTA. The arrows indicate the precipitates in the dentinal tubules. 2\% BG/MTA group showed denser precipitates in the dentinal tubules 

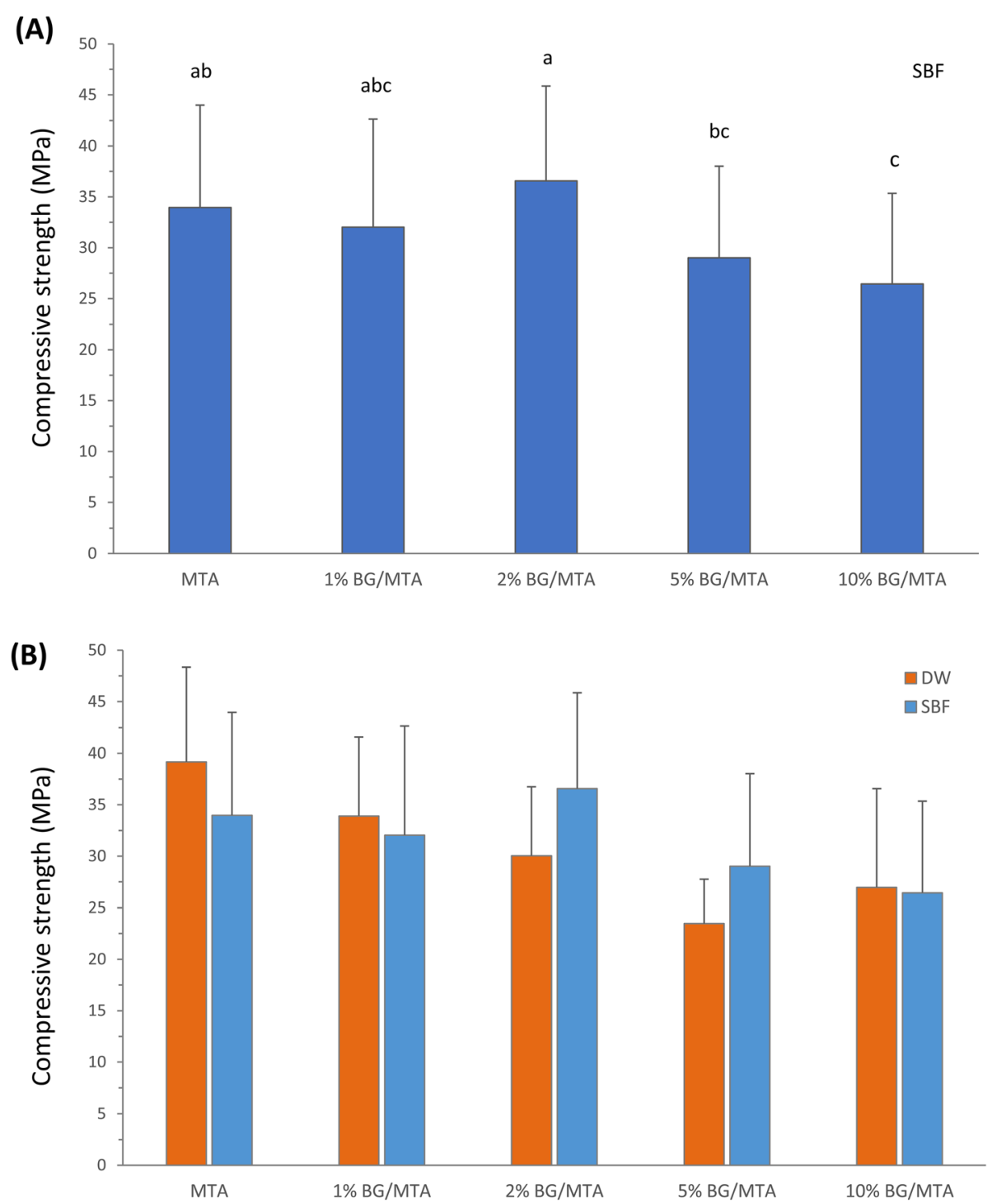

Fig. 3 A Results of the compressive strength. Results of experimental groups in SBF storage solution for 7 days. Same superscript means no statistical significance $(p>0.05)$. B The results of experimental groups in comparison of DW and SBF as storage solutions

\section{FE-SEM analysis}

Figure 2 shows the FE-SEM analysis results after the push-out bond strength measurements of the groups. In all groups, precipitates were observed in the dentinal tubules. Among all groups, the $2 \%$ BG/MTA group showed a denser precipitate infiltration (Fig. 2(C)).

\section{Compressive strength}

The compressive strength results are illustrated in Fig. 3. Among the specimens stored in SBF for 7 days, the $2 \%$ BG/MTA group showed the highest compressive strength (Fig. 3(A)). The control group and the 1 and $2 \%$ BG/MTA groups showed statistically higher intensities than that of the other BG/MTA groups $(p<0.05)$. Comparing the compressive strength results between DW and SBF that were storage solutions, the 2 and 5\% BG/ MTA groups showed a tendency to increase the compressive strength in SBF compared to DW (Fig. 3(B)). No significant interaction was observed between the materials and storage solution by two-way ANOVA $(p>$ 0.05).

\section{Setting time}

Table 2 showed the setting time results for the groups. Compared to the MTA group, the setting time of all experimental groups decreased. The reduction of setting time from the MTA group (428.3 min) were the 1, 2\% BG/MTA groups (398.3 and $401.0 \mathrm{~min}$ ) respectively. 
Table 2 Setting time ( $\mathrm{min}$ ) of the groups

\begin{tabular}{ll}
\hline Groups & Setting time (min) \\
\hline MTA & $428.33(11.93)$ \\
$1 \%$ BG/MTA & $398.33(18.82)$ \\
$2 \%$ BG/MTA & $401.00(26.89)$ \\
$5 \%$ BG/MTA & $406.02(25.16)$ \\
$10 \%$ BG/MTA & $416.67(42.52)$ \\
\hline
\end{tabular}

Values are written as means (standard deviation)

\section{Solubility}

The solubility results are presented in Table 3 . The solubility of the BG/MTA groups was slightly higher than that of the control group $(p<0.05)$.

\section{XRD analysis}

The XRD analysis results are presented in Fig. 4. In the MTA group and 1\% BG/MTA group, there was no difference between the analysis immediately after the setting and after the additional 7 days of SBF maturation in the graph. In the 2,5 , and $10 \% \mathrm{BG} / \mathrm{MTA}$ groups, the apatite peaks ranging from 40 to $50^{\circ}$ in the graph were increased in each SBF 7-day maturation specimen, compared to the control group analysis immediately after the setting (Fig. 4(B)).

\section{Discussion}

The biocompatibility and bioactivity of MTA have been demonstrated in a variety of endodontic treatment indications by laboratory and clinical studies. Though it has been widely used for 30 years, the disadvantage of decrease of physical properties, such as compressive strength, dimensional stability, and anti-washout property when in contact with periodontal tissue, blood, etc. is still one of the critical considerations [4, 7]. To overcome these characteristics, we examined BG, as an additive into MTA powder, which has been reported as a biomaterial with bone-like carbonated apatite-forming ability by the interaction between calcium ion and phosphate from tissue fluid. We evaluated the effect of BG on the physical properties of MTA, and demonstrated that the BG-containing MTA improved the physical properties in SBF condition or dentin bonding. We also

Table 3 Solubility (\%) of the groups

\begin{tabular}{ll}
\hline Groups & Solubility (\%) \\
\hline MTA & $1.17(0.19)^{c}$ \\
$1 \%$ BG/MTA & $1.70(0.36)^{a b}$ \\
$2 \%$ BG/MTA & $1.10(0.04)^{\mathrm{bc}}$ \\
$5 \%$ BG/MTA & $1.25(0.36)^{\mathrm{ab}}$ \\
$10 \%$ BG/MTA & $1.34(0.12)^{\mathrm{abc}}$ \\
\hline
\end{tabular}

Values are written as means (standard deviation)

Different superscript letters indicate significant differences between the materials $(p<0.05)$ investigated the optimal concentration of BG supplementation into MTA, which has an increasing effect or without hampering effect on the mechanical properties of MTA itself. Recently, several studies have been demonstrated the advantages of BG's high biocompatibility and remineralization ability of dentin [19-23, 32]. Within our knowledge, a single previous study [11] had been reported that the addition of BG showed the shortening effect of the setting time of MTA Angelus and experimental Portland cement. They examined the effect of supplementation of various concentrations of BG and calcium metasilicate (wollastonite) ranged from 10 to 30 $w t \%$. The study reported that BG addition over $10 \mathrm{wt} \%$ reduced the compressive strength of MTA, on the other hand, it has the shortening effect on the setting time without hampering the biological response. In our study, a significant important difference from the previous study [11] was found that supplementation of lower concentrations of BG which are 2 and/or $5 \mathrm{wt} \%$, has the effect to increase both the push-out bond strength and the compressive strength in SBF storage condition.

The push-out bond strength test is an effective method for evaluating the ability to resist detachment from restored sites [33]; we attempted to find the evidence of the strength by analyzing the SEM results. All experimental groups showed increased push-out bond strength after 7 days of SBF storage, and the value of the $2 \%$ BG/MTA group was the highest (Fig. 2). FE-SEM (Fig. 3) following the push-out bond strength was not analyzed statistically; however, it consistently showed results that could predict uniform and dense precipitation in the $2 \%$ BG/MTA group. It is speculated that the immediate precipitation by the formation of an amorphous calcium-phosphate layer on the BG induces mineralization of the tag-like layer to the dentinal tubular interface during mineralization; the extrusion bond strength appears to increase [34]. BG as an additive improved the handling properties because of an appropriate amount of silica self-agglomeration [22] during the hydration process with DW, and thus, the deposition in the tubules increased. To investigate this, an additional energy dispersive X-ray spectroscopy (EDS) analysis is required to analyze the composition of the precipitate in the tubule. In our preliminary study, we evaluated several mechanical and biological properties of various concentration of BG into MTA ranged from $1 \mathrm{wt} \%$ to 20 $w t \%$. We found that the supplementation of lower concentrations under $10 \mathrm{wt} \%$ of BG has the effect to increase both push-out bond strength to dentin and the compressive strength in SBF storage condition, especially in the $2 \mathrm{wt} \% \mathrm{BG} / \mathrm{MTA}$ showed the high push-out bond strength. In this study, we prepared the MTA or BG/ MTA groups were prepared using the MTA and 63S BG at four different concentrations: $1,2,5$, and $10 \mathrm{wt} \%$. The 


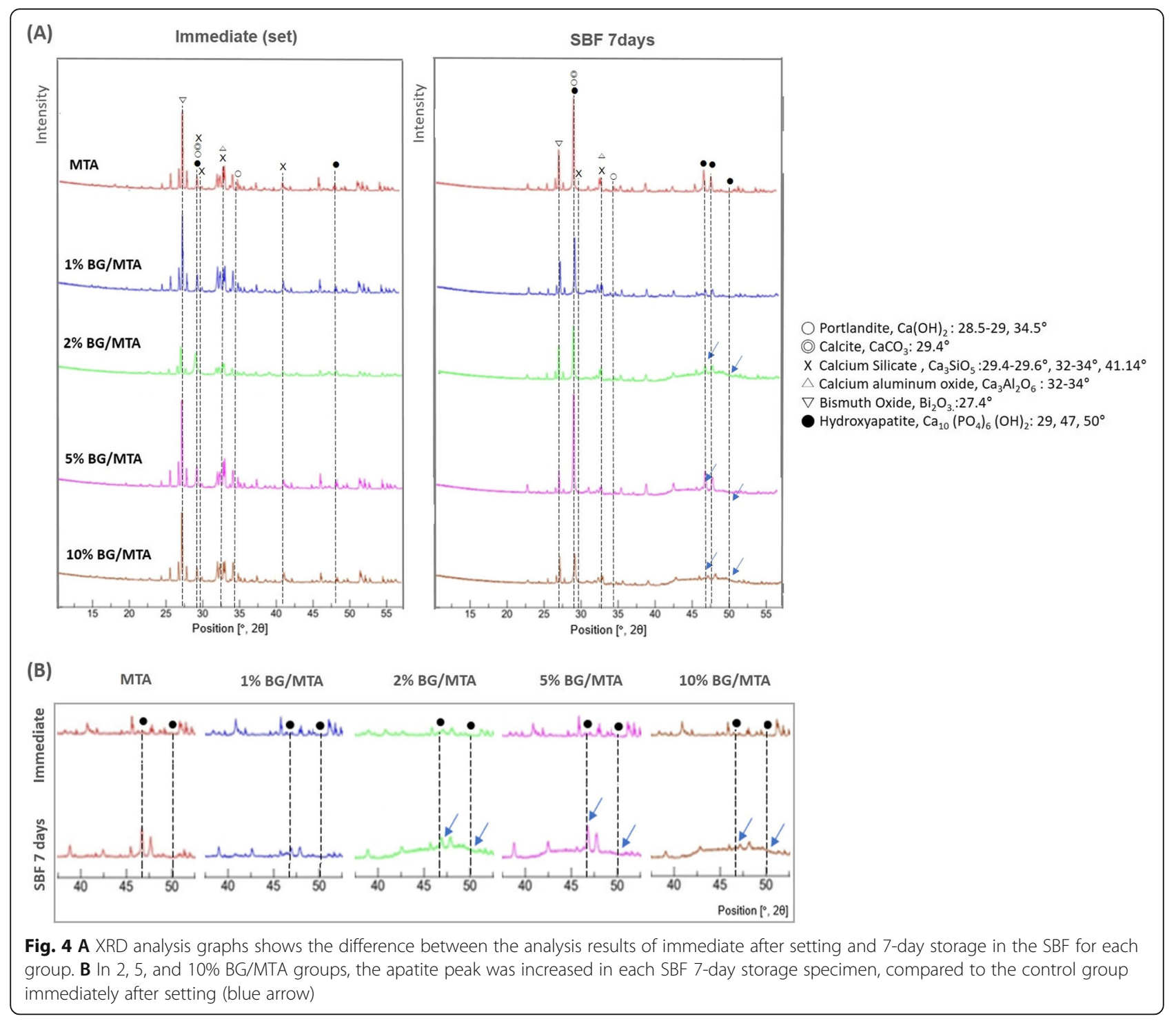

$\mathrm{L} / \mathrm{P}$ ratio of $\mathrm{DW}$ to the powder was 0.3 throughout the experiments, which was set according to the manufacturer's recommendations. We supplemented the BG into MTA powder so that the L/P ratio of BG/MTA composite was 0.3 , however, the pure MTA $L / P$ ratio might be different. It is speculated that the BG might influence the MTA hydration and setting reaction, due to their ion exchange between BG and phosphate from SBF solution. In addition, the different shapes and size of particles between BG and MTA powder might lead to the different setting reactions of MTA in the SBF solution, followed by the different mechanical properties. Consequently, our results suggest that the critical optimal concentration of addition of BG, which could take biological advantages in the SBF condition and increasing the amount of hydroxyapatite by BG without hampering effect on the mechanical properties, might be considered ranged from 2 to $5 \mathrm{wt} \%$.

Compressive strength is considered necessary in the evaluation of restorative MTA [35]. A comparison experiment was conducted to confirm the effectiveness of BG in SBF by dividing it into two storage solutions of DW and SBF. In the DW groups, the compressive strength decreased as the BG content increased, and the MTA group and 1 and $2 \%$ BG/MTA groups showed the highest values. The MTA and control groups only presented a significant decrease in SBF storage compared to the DW storage groups. Nekoofar et al. [9] reported that the compressive strength of MTA tends to decrease in SBF because of the decrease in the formation of acicular crystals. Therefore, it is speculated that this was the cause of the decrease in compressive strength in the 
SBF. In the SBF storage groups, the $2 \%$ BG/MTA group showed the highest value, and the 2 and 5\% BG/MTA groups showed an increased compressive strength value compared to DW storage. The mineralization effect of BG compensated for the compressive strength of MTA, which was reduced in SBF. Skallevold et al. [18] reported that the glass composition of BG contributes to poor mechanical properties because of its fragility. Our results showed that the compressive strength of the 10\% BG/ MTA group, which did not increase further even under SBF conditions, may be responsible for the amount of fragile glass content rather than the increase in the amount of hydroxyapatite. The $27 \mathrm{mM} \mathrm{HCO3-} \mathrm{Tris} \mathrm{SBF}$ was used as the SBF storage solution in this study. The composition of $27 \mathrm{mM}$ HCO3- Tris SBF is a component closer to plasma (27 mM HCO3- and $103 \mathrm{mM} \mathrm{Cl}-)$ than the original SBF $(4.2 \mathrm{mM} \mathrm{HCO} 3-$ and $148 \mathrm{mM} \mathrm{Cl}-)$ [30], and it had an enhanced ability to induce apatitelike calcium phosphate formation [23]. According to previous studies, there is a possibility of the autogenous precipitation of calcium phosphate when stored at $37^{\circ} \mathrm{C}$ for several weeks [21, 36]; thus, SBF was exchanged once every 2 days in this study.

Setting time is a property for the stable maintenance of endodontic restorative materials. In this study, all BG/ MTA groups showed a decrease in the setting time (Table 2). The initial hydration process of MTA occurs on the outer surface of the particles, and the rate of this process is affected by the particle size and the powderto-liquid ratio that is determined from the setting time data. The particle sizes of MTA and BG used in this study ranged from to $1-30 \mu \mathrm{m}$ [37] and $<20 \mu \mathrm{m}$ [22], respectively. The effect of increased surface area and reactivity caused by the small size of BG [11,38-40] could lead to a reduction in the setting time. The known setting time of the MTA is 4-6h; however, the setting time of the experimental MTA was found to be 6-7 h (398$428 \mathrm{~min}$ ), which is slightly longer. There are two types of specifications used for the method of measuring the setting time suggested in MTA-related studies [27]: ISO 6876 , dental root canal sealing materials, and ISO 9917, and dentistry water-based cements. The ISO 6876 method is similar to the initial setting time because of the difference in the mold containing the specimen, and the ISO 9917 method is similar to the final setting time. We demonstrated along setting time by referring to the ISO 9917-1 method; however, it does not deviate significantly from the general range.

The solubility test is one of the most important requisites for endodontic restorative materials because it directly contacts the periodontal tissue fluids [41] and copes with the sealing of the wound. The solubility of all BG/MTA groups was slightly higher than that of the MTA group (Table 3); however, all groups showed values less than $3 \%$, which is within the acceptable ISO 6876 range [31]. As the conditions for measuring the solubility of ISO were DW, calcium or phosphate ions could not be utilized in the surrounding solution [18, 42]. Therefore, it is assumed that a lower solubility value will be obtained if it is re-measured in a physiological solution environment where the action of BG can appear.

XRD was used to investigate the existence of hydroxyapatite formation in the experimental groups after 7 days of storage in SBF (Fig. 4); the $29^{\circ}$ peak [34, 43] increased in the MTA, 1, 2, and 5\% BG/MTA groups, and $47^{\circ}$ and $50^{\circ}$ peaks $[34,43]$ increased in the 2,5 , and $10 \%$ BG/ MTA groups. Although there is a limitation in that XRD only analyzes surface components, it showed that the BG/MTA group can additionally form hydroxyapatite. However, the 2\% BG/MTA group, which showed the highest compressive strength and push-out bond strength in SBF, did not exhibit the highest hydroxyapatite formation. From a clinical point of view, these results suggest that $2 \%$ BG/MTA improved the handling properties properly during the hydration process before setting; however, after setting, it contributed to the maintenance of physical properties by maintaining the appropriate amount of MTA along with an increase in the appropriate amount of hydroxyapatite by BG [18].

The possibility of reducing physical properties with BG at a high concentration of $10 \%$ or more can be inferred from previous studies dealing with GI or white Portland cement $[11,43]$. However, to improve various physical properties at a specific concentration of $2 \%$ BG, further studies such as the component analysis of tubule precipitation are still required.

The biocompatibility of dental materials for perforation repair is an important characteristic. The MTA is a well-known biocompatible sealing material used for endodontic treatment [2]. The biocompatibility of BG has been proven to be an appropriate applicable material in the regeneration area $[44,45]$. Although our investigation has not been performed, further study is necessary to evaluate the biocompatibility of BG-supplemented MTA, which includes viability, proliferation, and migration of dental pulp cells.

\section{Conclusion}

Within the limitations of this study, it was verified that the BG-added MTA increased dentin push-out bond strength and compressive strength under SBF storage. There was no increase in setting time of MTA with BG, and the solubility was clinically acceptable within $3 \%$. In SBF storage condition, increase hydroxyapatite leaks were shown in the BG-added MTA group. The addition of BG did not negatively affect the hydration and setting reactions of MTA, and as the production of 
hydroxyapatite was increased in SBF condition, MTA with BG could be considered to be utilized as a viable biocompatible restorative material for the clinical endodontics.

\section{Abbreviations}

BG: Bioactive glass; DW: Distilled water; EDTA: Ethylenediaminetetraacetic acid; MTA: Mineral trioxide aggregates; SBF: Simulating body fluid; XRD: X-ray diffraction

\section{Acknowledgements}

This research was supported by the Bio \& Medical Technology Development Program of the National Research Foundation (NRF) \& funded by the Korean government (MSIP\&MOHW) (No. 2017M3A9E4048170) and NRF (No.2019R1G1A1100082). This work was also supported by a grant from Kyung Hee University in 2020 (KHU-20201233).

We would like to thank Editage (www.editage.co.kr) for English language editing.

\section{Authors' contributions}

J.J designed, planned and coordinated the study. J.K. and J.J wrote the manuscript. J.K., H.K and S.K participated in the experiments. S.O., S.C., D.K. and K.C played a substantial role in the interpretation of results and discussion. All authors reviewed the manuscript. The author(s) read and approved the final manuscript.

\section{Funding}

This research was supported by the Bio \& Medical Technology Development Program of the National Research Foundation (NRF) \& funded by the Korean government (MSIP\&MOHW) (No. 2017M3A9E4048170) and NRF (No.2019R1G1A1100082). This work was also supported by a grant from Kyung Hee University in 2020 (KHU-20201233).

\section{Availability of data and materials}

The datasets during and/or analyzed during the current study available from the corresponding author or reasonable request.

\section{Declarations}

\section{Ethics approval and consent to participate}

The experimental protocol using human teeth was reviewed and approved by the Kyung Hee University Institutional Review Board (KHU-1808-1), and all methods were performed in accordance with the Declaration of Helsinki guidelines and regulations. The included teeth were obtained from patients whose teeth were indicated for extraction, and informed consent was obtained.

\section{Consent for publication}

Not applicable.

\section{Competing interests}

The authors declare that they have no competing interests.

\section{Author details \\ 'Department of Conservative Dentistry, Graduate School, Kyung Hee University, Seoul, South Korea. ${ }^{2}$ Department of Conservative Dentistry, Kyung Hee University Dental Hospital, Seoul, South Korea. ${ }^{3}$ Department of Conservative Dentistry, School of Dentistry, Kyung Hee University, 26 Kyungheedae-ro, Dongdaemun-gu, Seoul 02447, Republic of Korea. ${ }^{4}$ Department of Conservative Dentistry and Dental Research Institute, School of Dentistry, Seoul National University, Seoul, South Korea.}

Received: 6 July 2021 Accepted: 7 October 2021

Published online: 24 November 2021

\section{References}

1. Parirokh M, Torabinejad M. Mineral trioxide aggregate: a comprehensive literature review--part I: chemical, physical, and antibacterial properties. $J$ Endod. 2010;36(1):16-27. https://doi.org/10.1016/j.joen.2009.09.006.
2. Torabinejad M, Chivian N. Clinical applications of mineral trioxide aggregate. J Endod. 1999;25(3):197-205. https://doi.org/10.1016/S0099-2399(99)80142-3.

3. Main C, Mirzayan N, Shabahang S, Torabinejad M. Repair of root perforations using mineral trioxide aggregate: a long-term study. J Endod. 2004;30(2):80-3. https://doi.org/10.1097/00004770-200402000-00004.

4. Parirokh $\mathrm{M}$, Torabinejad $\mathrm{M}$. Mineral trioxide aggregate: a comprehensive literature review--part III: clinical applications, drawbacks, and mechanism of action. J Endod. 2010;36(3):400-13. https://doi.org/10.1016/j.joen.2009.09.009.

5. Lee BN, Hwang YC, Jang JH, Chang HS, Hwang IN, Yang SY, et al. Improvement of the properties of mineral trioxide aggregate by mixing with hydration accelerators. J Endod. 2011;37(10):1433-6. https://doi.org/1 0.1016/j.joen.2011.06.013.

6. Jang JH, Lee CO, Kim HJ, Kim SG, Lee SW, Kim SY. Enhancing effect of Elastinlike polypeptide-based matrix on the physical properties of mineral trioxide aggregate. J Endod. 2018;44(11):1702-8. https://doi.org/10.1016/j. joen.2018.07.017.

7. Hsieh SC, Teng NC, Lin YC, Lee PY, Ji DY, Chen CC, et al. A novel accelerator for improving the handling properties of dental filling materials. J Endod. 2009;35(9):1292-5. https://doi.org/10.1016/j.joen.2009.06.007.

8. VanderWeele RA, Schwartz SA, Beeson TJ. Effect of blood contamination on retention characteristics of MTA when mixed with different liquids. J Endod. 2006;32(5):421-4. https://doi.org/10.1016/j.joen.2005.09.007.

9. Nekoofar MH, Stone DF, Dummer PM. The effect of blood contamination on the compressive strength and surface microstructure of mineral trioxide aggregate. Int Endod J. 2010;43(9):782-91. https://doi.org/10.1111/j.1365-2 591.2010.01745.x

10. Ber BS, Hatton JF, Stewart GP. Chemical modification of proroot mta to improve handling characteristics and decrease setting time. J Endod. 2007; 33:1231-4. https://doi.org/10.1016/j.joen.2007.06.012.

11. Flores-Ledesma A, et al. Bioactive materials improve some physical properties of a MTA-like cement. Mater Sci Eng C Mater Biol Appl. 2017;71: 150-5. https://doi.org/10.1016/j.msec.2016.09.079.

12. Oloomi K, Saberi E, Mokhtari H, Mokhtari Zonouzi HR, Nosrat A, Nekoofar $\mathrm{MH}$, et al. Evaluation of the effect of blood contamination on the compressive strength of MTA modified with hydration accelerators. Restor Dent Endod. 2013;38(3):128-33. https://doi.org/10.5395/rde.2013.38.3.128.

13. Kim HJ, Lee D, Cho S, Jang JH, Kim SG, Kim SY. Improvement of the bonding properties of mineral trioxide aggregate by elastin-like polypeptide supplementation. Scanning. 2019;3484396:2019-8. https://doi.org/10.1155/2 019/3484396.

14. Prasad A, et al. A comparative evaluation of the effect of various additives on selected physical properties of white mineral trioxide aggregate. J Conserv Dent. 2015;18(3):237-41. https://doi.org/10.4103/0972-0707.157263.

15. Chang S-W. Chemical characteristics of mineral trioxide aggregate and its hydration reaction. Restor Dent Endod. 2012;37(4):188-93. https://doi.org/10. 5395/rde.2012.37.4.188.

16. Nekoofar MH, Oloomi K, Sheykhrezae MS, Tabor R, Stone DF, Dummer PMH. An evaluation of the effect of blood and human serum on the surface microhardness and surface microstructure of mineral trioxide aggregate. Int Endod J. 2010;43(10):849-58. https://doi.org/10.1111/j.1365-2591.2010.01750.x.

17. Hench LL, Jones JR. Bioactive glasses: frontiers and challenges. Front Bioeng Biotechnol. 2015;3:194. https://doi.org/10.3389/fbioe.2015.00194.

18. Skallevold HE, Rokaya D, Khurshid Z, Zafar MS. Bioactive glass applications in dentistry. Int J Mol Sci. 2019;20(23):5960. https://doi.org/10.3390/ijms20235960.

19. Zhu N, Chatzistavrou X, Ge L, Qin M, Papagerakis P, Wang Y. Biological properties of modified bioactive glass on dental pulp cells. J Dent. 2019;83: 18-26. https://doi.org/10.1016/j.jdent.2019.01.017.

20. Tiskaya M, Shahid S, Gillam D, Hill R. The use of bioactive glass (BAG) in dental composites: a critical review. Dent Mater. 2021;37(2):296-310. https:// doi.org/10.1016/j.dental.2020.11.015

21. Jang J-H, Lee MG, Ferracane JL, Davis H, Bae HE, Choi D, et al. Effect of bioactive glass-containing resin composite on dentin remineralization. J Dent. 2018;75:58-64. https://doi.org/10.1016/j.jdent.2018.05.017.

22. Kim H-J, et al. Effects of bioactive glass incorporation into glass ionomer cement on demineralized dentin. Sci Rep. 2021;11:1-10.

23. Tas AC. Synthesis of biomimetic ca-hydroxyapatite powders at $37 \mathrm{C}$ in synthetic body fluids. Biomaterials. 2000;21 (14):1429-38. https://doi.org/10.1 016/s0142-9612(00)00019-3.

24. Gancedo-Caravia L, Garcia-Barbero E. Influence of humidity and setting time on the push-out strength of mineral trioxide aggregate obturations. J Endod. 2006;32(9):894-6. https://doi.org/10.1016/j.joen.2006.03.004. 
25. Reyes-Carmona JF, Felippe MS, Felippe WT. The biomineralization ability of mineral trioxide aggregate and Portland cement on dentin enhances the push-out strength. J Endod. 2010;36(2):286-91. https://doi.org/10.1016/j. joen.2009.10.009.

26. International Organization for Standardization. Dentistry Water-based cements. Part 1 Powderliquid acid-base cements. In International Standard ISO 9917-12007. 2nd ed. Geneva: ISO; 2007.

27. Ha WN, Nicholson T, Kahler B, Walsh LJ. Mineral trioxide aggregate-a review of properties and testing methodologies. Materials (Basel). 2017;10(11):1261. https://doi.org/10.3390/ma10111261.

28. Camilleri J. Evaluation of the physical properties of an endodontic Portland cement incorporating alternative radiopacifiers used as root-end filling material. Int Endod J. 2010;43(3):231-40. https://doi.org/10.1111/j.1365-2 591.2009.01670.x.

29. Corral Nunez C, Covarrubias C, Fernandez E, Oliveira OBJ. Enhanced bioactive properties of BiodentineTM modified with bioactive glass nanoparticles. J Appl Oral Sci. 2017;25(2):177-85. https://doi.org/10.1590/1 678-77572016-0209.

30. Kokubo T, Takadama H. How useful is SBF in predicting in vivo bone bioactivity? Biomaterials. 2006;27(15):2907-15. https://doi.org/10.1016/J. biomaterials.2006.01.017.

31. International Organization for Standardization. Dental root canal sealing materials. In: International Standard ISO 68762001. 2nd ed. Geneva: ISO; 2001.

32. Parirokh $\mathrm{M}$, Torabinejad $\mathrm{M}$, Dummer PMH. Mineral trioxide aggregate and other bioactive endodontic cements: an updated overview - part l: vital pulp therapy. Int Endod J. 2018:51(2):177-205. https://doi.org/10.1111/iej.12841.

33. Alamoudi RA, Abu Zeid ST. Effect of Irrigants on the push-out bond strength of two bioceramic root repair materials. Materials (Basel). 2019; 12(12):1921. https://doi.org/10.3390/ma12121921.

34. Reyes-Carmona JF, Felippe MS, Felippe WT. Biomineralization ability and interaction of mineral trioxide aggregate and white Portland cement with dentin in a phosphate-containing fluid. J Endod. 2009;35(5):731-6. https:// doi.org/10.1016/j.joen.2009.02.011.

35. Islam I, Chng HK, Yap AUJ. Comparison of the physical and mechanical properties of MTA and Portland cement. J Endod. 2006;32(3):193-7. https:// doi.org/10.1016/j.joen.2005.10.043.

36. Pan H, Zhao X, Darvell BW, Lu WW. Apatite-formation ability-predictor of "bioactivity"? Acta Biomater. 2010;6(11):4181-8. https://doi.org/10.1016/j.a ctbio.2010.05.013.

37. Camilleri J, Pitt Ford T. Mineral trioxide aggregate: a review of the constituents and biological properties of the material. Int Endod J. 2006: 39(10):747-54. https://doi.org/10.1111/j.1365-2591.2006.01135.x.

38. Camilleri J. Characterization of hydration products of mineral trioxide aggregate. Int Endod J. 2008;41(5):408-17. https://doi.org/10.1111/j.1365-2 591.2007.01370.x.

39. Camilleri J. Hydration mechanisms of mineral trioxide aggregate. Int Endod J I. 2007;40(6):462-70. https://doi.org/10.1111/j.1365-2591.2007.01248.x.

40. Komabayashi T, Spångberg LS. Comparative analysis of the particle size and shape of commercially available mineral trioxide aggregates and Portland cement: a study with a flow particle image analyzer. J Endod. 2008;34(1):948. https://doi.org/10.1016/j.joen.2007.10.013.

41. Alzraikat H, Taha NA, Salameh A. A comparison of physical and mechanical properties of biodentine and mineral trioxide aggregate. J Res Med Dent Sci. 2016;4(2):121-6. https://doi.org/10.5455/jrmds.2016429.

42. Kaup M, Schafer E, Dammaschke T. An in vitro study of different material properties of biodentine compared to ProRoot MTA. Head Face Med. 2015; 11(1):16. https://doi.org/10.1186/s13005-015-0074-9.

43. Yli-Urpo H, Lassila LV, Närhi T, Vallittu PK. Compressive strength and surface characterization of glass ionomer cements modified by particles of bioactive glass. Dent Mater. 2005;21(3):201-9. https://doi.org/10.1016/j.denta 1.2004.03.006.

44. Rahaman MN, Day DE, Sonny Bal B, Fu Q, Jung SB, Bonewald LF, et al. Bioactive glass in tissue engineering. Acta Biomater. 2011;7(6):2355-73. https://doi.org/10.1016/j.actbio.2011.03.016.

45. Long Y, Liu S, Zhu L, Liang Q, Chen X, Dong Y. Evaluation of pulp response to novel bioactive glass pulp capping materials. J Endod. 2017;43(10):164750. https://doi.org/10.1016/j.joen.2017.03.011.

\section{Publisher's Note}

Springer Nature remains neutral with regard to jurisdictional claims in published maps and institutional affiliations.

\section{Ready to submit your research? Choose BMC and benefit from}

- fast, convenient online submission

- thorough peer review by experienced researchers in your field

- rapid publication on acceptance

- support for research data, including large and complex data types

- gold Open Access which fosters wider collaboration and increased citations

- maximum visibility for your research: over $100 \mathrm{M}$ website views per year

At BMC, research is always in progress.

Learn more biomedcentral.com/submissions 